\title{
Sex-specific foraging behaviour and a field sexing technique for Endangered African penguins
}

\author{
L. Pichegru ${ }^{1, *}$, T. $\operatorname{Cook}^{1}$, J. Handley ${ }^{2}$, N. $\operatorname{Voogt}^{2}$, J. Watermeyer ${ }^{2}$, L. Nupen ${ }^{1}$, \\ C. D. McQuaid ${ }^{2}$
}

${ }^{1}$ DST/NRF Centre of Excellence at the Percy FitzPatrick Institute, University of Cape Town, Rondebosch 7701, South Africa ${ }^{2}$ Department of Zoology and Entomology, Rhodes University, Grahamstown 6140, South Africa

\begin{abstract}
Sexual differences in at-sea behaviour of seabirds often derive from size dimorphism and may lead to both resource partitioning and diverging threats between the sexes. Spheniscids are among the least dimorphic of the seabird families and are the most threatened. In many instances, diet differs between the sexes in penguins, but few studies have compared their foraging behaviour, partly because of the difficulty of identifying sexes in the field. We derived a discriminant function analysis that predicts the sex of African penguins Spheniscus demersus with $>90 \%$ confidence, using only beak length and depth. We also deployed GPS-time-depth recorders on male and female penguins breeding on 2 of their largest colonies in South Africa over 2 consecutive breeding seasons and compared their at-sea behaviour. Foraging effort (time spent at sea, distance covered) showed greater variance with clutch mass and between years and colonies than between sexes. However, although maximum diving capabilities were similar, males dived deeper and longer on average than females. Females compensated by increasing their diving frequency, which resulted in similar volumes of water being explored, and foraged over larger foraging areas. There was also some spatial separation between sexes, although foraging range overlap differed markedly ( 35 to $83 \%$ ) between years and islands, presumably reflecting prey availability and the need to minimise between-sex competition. The results suggest potential niche partitioning between the sexes in African penguins, but could also be a passive consequence of sexual dimorphism driven primarily by sexual selection. Female behaviour may make them more at risk from predation or oiling events, highlighting the possibility of sex-dependent vulnerability in this Endangered species.
\end{abstract}

KEY WORDS: Diving behaviour · Foraging area $\cdot$ Sexual size dimorphism $\cdot$ Discriminant function analysis $\cdot$ Spheniscus demersus $\cdot$ Cloaca measurement $\cdot$ Clutch size $\cdot$ Morphology

\section{INTRODUCTION}

Seabirds breed in a highly variable environment, and the survival of their small broods is dependent on care by both parents. However, diverging energetic constraints between the sexes, deriving for example from egg production (e.g. Welcker et al. 2009), nest defence (e.g. Fraser et al. 2002) or differential nest attendance (e.g. incubation conducted by a single sex, as in the emperor penguin Aptenodytes forsteri;
Williams 1995) can lead to differential behaviour at sea. Similarly, physical differences in dimorphic species also result in sex-specific foraging strategies (Selander 1966), due to larger energy reserves (e.g. Gonzàlez-Solìs \& Croxall 2005) or larger physical attributes. Dissimilarities in foraging behaviour between sexes can have crucial implications for conservation, exposing males and females to different threats, notably as by-catch in fisheries (Bugoni et al. 2010), which can induce differential mortality rates, 
and skewed sex ratios in populations (Ryan \& BoixHinzen 1999). Such sex-biased mortality has serious long-term consequences for fecundity and population growth rate of these long-lived birds (Mills \& Ryan 2005), and could eventually lead to the extinction of small populations (Dale 2001).

Spheniscids are generally less markedly dimorphic than other seabirds (Fairbairn \& Shine 1993), although all penguins exhibit some degree of sexual size dimorphism (Williams 1995). To date, the number of studies investigating sexual differences in at-sea behaviour of penguins remains fairly low, partly because the sexes are similar in overall appearance, which renders sexual differentiation in the field difficult, and partly because many spheniscid species are threatened with extinction (10 of the 17 species are classified at least as Vulnerable to extinction by the International Union for Conservation of Nature; www.iucn.org), hence limiting study possibilities. However, studies of their ecology and behaviour are particularly needed to develop effective conservation plans.

In some penguin species, sexual differences in atsea behaviour are a direct consequence of differential parental duty leading to temporal and spatial segregation of prey between foraging periods of both sexes (e.g. in the emperor penguin, Wienecke \& Robertson 1997, or the macaroni penguin Eudyptes chrysolophus, Barlow \& Croxall 2002). When parental duty is equally shared, differences between males and females generally tend to concern diet and diving behaviour, and are mainly attributable to sexual size dimorphism (SSD). The larger beak of the larger sex could allow it to catch different prey (e.g. gentoo penguins Pygoscelis papua, Volkman et al. 1980; Adélie penguins $P$. adeliae, Ainley \& Emison 1972), and the larger sex usually dives deeper, presumably because of the allometry of diving capacities (e.g. little penguins Eudyptula minor Bethge et al. 1997, Halsey et al. 2006). Potential divergences in foraging areas between males and females have been suggested by stable isotope studies (e.g. nonbreeding rockhopper penguins Eudyptes chrysocome chrysocome, Dehnhard et al. 2011), but such differences could also be attributed to different prey caught within the same foraging area. To our knowledge, Adélie penguins are the only studied species that share equal parental duty during chick-rearing but exhibit large sexual differences in diet, foraging location and trip duration, suggesting potential niche partitioning between sexes with a consequent reduction in intra-specific competition (Clarke et al. 1998, Beaulieu et al. 2010).
In the genus Spheniscus, some evidence exists of sexual differences in at-sea behaviour that are attributable to SSD. Male Humboldt penguins Spheniscus humboldti showed greater maximum diving capabilities than females, but foraged on average at the same depths (Taylor et al. 2002). In Magellanic penguins $S$. magellanicus, males fed on a larger proportion of fish and females on a larger proportion of squids, presumably because of the larger beaks of males, which allowed them to catch fish more effectively (Forero et al. 2002). Dive depths differed between the sexes only during the incubation period (Raya Rey et al. 2012), which was hypothesised as driven by a decrease in prey availability and made possible by the larger size of the males (Walker \& Boersma 2003). No difference was observed in foraging or diving effort or foraging area during chick rearing (Raya Rey et al. 2010, 2012) or the winter migration (Pütz et al. 2007).

The African penguin Spheniscus demersus is endemic to southern Africa and has been recently downgraded to Endangered due to ongoing, dramatic decreases in its numbers (Crawford et al. 2011; www.iucnredlist.org). The causes of this decline are unclear, and appropriate conservation of this emblematic species requires detailed knowledge of its ecology, particularly during breeding. The way in which chick provisioning load is shared between sexes in African penguins is poorly understood, partly because studies on sex-specific foraging behaviour in the species are rendered difficult by the similar appearance of the 2 sexes in the field. Therefore, the aims of our study were 2-fold: (1) to determine the morphometrics that differ most strongly between male and female African penguins in order to allow sex determination in the field whilst minimising handling time; (2) to assess potential differences between the sexes in at-sea behaviour. We postulated that males would dive deeper and longer than females due to their greater mass-related diving capacities. We also postulated that they would travel farther than females, because travelling costs should decrease with body size (Schmidt-Nielsen 1972), and consequently males would be more exposed to threats, such as oil slicks or predators (e.g. Lima \& Dill 1990), than females.

\section{MATERIALS AND METHODS}

Data on breeding African penguins were collected between 2009 and 2011 on Bird Island (33 50' S, $\left.26^{\circ} 17^{\prime} \mathrm{E}\right)$ and St Croix Island $\left(33^{\circ} 48^{\prime} \mathrm{S}, 25^{\circ} 46^{\prime} \mathrm{E}\right)$ in 
Nelson Mandela Bay, South Africa. Bird Island hosts ca. 2500 breeding pairs, while St Croix is home to ca. 7500 pairs, although both colonies are currently decreasing (Crawford et al. 2011). Most African penguins on these islands breed between March and August. During this period, pairs share the care of their brood of 1 or 2 chicks, with 1 adult attending the nest while the partner is at sea.

\section{Sexing birds from general morphology, cloaca measurements and genetics}

Morphometric measurements were taken from every African penguin handled during our study. These included bill length, bill depth, flipper length and body mass. Bill measurements were done with dial-gauge Vernier callipers to the nearest $0.1 \mathrm{~mm}$ (see Fig. S1 in the supplement at www.int-res.com/ articles/suppl/n019p255_supp.pdf). Flipper length was measured from body to wing tip with a ruler to the nearest millimetre. Mass of birds was measured using a $5 \mathrm{~kg}$ spring balance with $25 \mathrm{~g}$ calibration and a strap placed securely around the penguin. Wherever possible, all measurements were done on both partners within a pair. In April 2010 and March 2011, additional cloaca measurements were performed on both members of incubating pairs that were not part of the study of at-sea behaviour. Cloaca measurements are sometimes used to determine an individual's sex in monomorphic species during the incubation period (Boersma \& Davies 1987), as female cloacas remain dilated for a period of time after laying eggs. Measurements were done to the nearest $0.1 \mathrm{~mm}$ with dial-gauge Vernier callipers and included cloaca width and cloaca dorso-ventral length, following Boersma \& Davies (1987). Prior to measurement, the cloaca was swabbed with a $10 \%$ alcohol solution to cause contraction of the sphincter. This maximises differences between the sexes, as the female cannot contract her swollen cloaca to the same degree as the male (Samour et al. 1983, Boersma \& Davies 1987).

For the 109 pairs used in the at-sea behaviour study, we initially assumed that, within a pair, the larger bird was the male (Cooper 1972). For 98 of these pairs, 1 partner was larger for all 4 bodily measurements. For the remaining 11 pairs, 1 partner had larger values for 3 out of 4 bodily measurements. We subsequently performed a backward stepwise discriminant function analysis (Jennrich 1977) on the total sample of 109 pairs to determine which bodily measurements best discriminated the sexes (a priori probabilities: males: 50\%, females: $50 \%$ ), using Sta- tistica 8.0 (StatSoft). The model significance was tested by the Wilks' lambda test, which varies between 0 (perfect discrimination) and 1 (no discrimination). Since it is not uncommon to obtain good classification when testing the classification functions on the cases from which these were computed, it is advisable to perform a cross-validation on cases of known categories that were not used in the analysis (Jennrich 1977). For this, we used birds from the cloaca study (55 pairs). We assumed that, within a pair, the bird with the largest values for cloaca width + length was the female, as has been observed in other species of birds (Boersma \& Davies 1987). To test whether this assumption was accurate in the African penguin, cover feathers were collected from a sub-sample of 12 pairs randomly chosen within this group, and sex was determined using molecular techniques. Molecular sexing was carried out following Fridolfsson \& Ellegren (1999), using primers CHD 2550F and 2718R. Introns CHD1Z and CHD1W were amplified using standard polymerase chain reaction (PCR) techniques. The product underwent electrophoresis on a $2 \%$ agarose gel. Female penguins displayed 2 (CHD1W and CHD1Z) bands, whereas males displayed only 1 band. We then tested our classification functions on the dataset from the cloaca study and consequently assessed their predictive power.

\section{Data-loggers and foraging parameters}

The at-sea behaviour of adult penguins raising chicks of 1 to 3 wk old was studied at Bird and St Croix Islands. Birds were equipped with GPS-TD loggers (a GPS recorder combined with a time-depth recorder; $96 \times 39 \times 26.5 \mathrm{~mm}$; earth \& OCEAN Technologies) that record latitude and longitude at $1 \mathrm{~min}$ intervals to an accuracy of $<10 \mathrm{~m}$, and depth at $1 \mathrm{~s}$ intervals to the nearest $0.1 \mathrm{~m}$. Penguins weighed 2.3 to $4.6 \mathrm{~kg}$ (mean: $3.2 \pm 0.4 \mathrm{~kg}$ ). Devices weighed $70 \mathrm{~g}$ (1.5 to $3.0 \%$ of adult body mass; mean: $2.2 \%$ ), and were housed in streamlined fibre-composite containers. They were attached to the penguins' lower back feathers with waterproof tape, causing no damage to the plumage. Handling lasted $<6 \mathrm{~min}$ from capture to release. The day following deployment, the partner of the equipped bird and their chicks were weighed and measured. Nest sites were then monitored until the instrumented birds returned, allowing them to be recaptured and the logger removed, thus recording a single foraging trip per individual. Previous studies showed no significant difference in the foraging trip 
duration of instrumented versus control African penguins (Pichegru et al. 2010).

On retrieval of the devices, trip duration, horizontal path length at sea (at the surface), maximum distance from the colony and total vertical travel distance (VTD, defined as the sum of the depths of all dives multiplied by 2 to obtain distance, sensu Horning \& Trillmich, 1997) were calculated to estimate the birds' foraging effort. We also describe the diving behaviour of birds (diving rate, i.e. number of dives $\mathrm{h}^{-1}$ at sea, and dive depth and duration) using MultiTrace Dive Analysis (Jensen Software Systems), defining a feeding dive as $>3 \mathrm{~m}$ and diurnal (following Wilson \& Wilson 1990). These parameters were used to compare foraging behaviour between the sexes.

\section{Testing sexual differences in foraging behaviour}

We tested the effect of sex on foraging trip duration, path length, maximum distance from the colony and dives $\mathrm{h}^{-1}$ at sea using general linear models in $\mathrm{R}$ (R Development Core Team). Year (2009 or 2010) and colony (St Croix or Bird Island) were added as fixed effects because of the potential influence of environmental differences or variability. We set clutch mass (cumulative mass of chicks per nest) as a covariate to account for the combined effect of chick numbers and stage on foraging effort. We also built generalised linear mixed-effects models to test the effect of sex on dive depth and duration, with year and colony as fixed effects and bird identity as a random effect (in order to account for the effect of repeated individual dives).

To analyse the spatial overlap of foraging habitat between males and females, we conducted minimum convex polygon (MCP) analyses in Arcview GIS 3.1. We used the GPS locations of foraging dives (i.e. those to depths $>3 \mathrm{~m}$ ) as inferred by linear extrapolation based on time between GPS and dive records from the loggers. We estimated the total foraging range (MCP 100\%) of males and females from both colonies and both years of our study. We then determined the area used by both sexes, i.e. where foraging areas of males and females overlapped, and compared it to the total area used by all the birds in a single year for each colony. We calculated the proportion (\%) of the entire foraging range of the colony for that year that was represented by this overlap. Finally, we estimated the proportion of each colony's total foraging area used only by one of the sexes for each year and each island.

\section{RESULTS}

\section{Sexing African penguins}

Molecular sexing of a sub-sample of 12 pairs randomly chosen from the cloaca dataset (55 pairs) showed no difference from the sex that had been assigned in advance by comparing cloaca dimensions. We therefore assumed that it is possible to use cloaca measurements to sex incubating African penguins when both birds within a pair can be measured, even when the egg-laying date is unknown.

Only 2 parameters were selected by the backward stepwise discriminant function analysis that was performed on 4 body measurements of 109 pairs of chick-rearing African penguins (Table 1). Subsequent classification functions for determining sex comprised bill length (BL) and bill depth (BD):

$$
\begin{aligned}
& \mathrm{C} 1=-350.677+(7.589 \mathrm{BL})+(9.320 \mathrm{BD}) \\
& \mathrm{C} 2=-292.189+(6.962 \mathrm{BL})+(8.421 \mathrm{BD})
\end{aligned}
$$

Each function allowed the computation of a score for each sex (if $\mathrm{C} 1>\mathrm{C} 2$, sex is male; if $\mathrm{C} 1<\mathrm{C} 2$, sex is female). Classification functions correctly classified the sex of $86 \%$ of birds (87\% of males, $84 \%$ of females). Cross-validation was performed on the dataset from the cloaca study (55 pairs), with classification functions correctly classifying $92 \%$ of the birds of known sex (93\% of males, $91 \%$ of females). We therefore considered our functions to yield high classification power and used them to classify 6 birds from the at-sea behaviour study for which sex was unknown because the partner had not been measured.

Combining the at-sea behaviour dataset with the cloaca dataset (total $\mathrm{N}=334$ birds), we were able to describe the morphology of each sex of the African penguin. On average, males were larger than females for all measurements, with a $15 \%$ sexual size dimorphism in body mass (Table 2). Overall, there was overlap between the 2 sexes in all body characters (Fig. 1).

Table 1. Spheniscus demersus. Result of the backward stepwise discriminant function analysis for discriminating sex in the African penguin (overall Wilks' lambda $=0.425, F_{4,215}=$ 144.29, $\mathrm{p}<0.0001$ ). The Wilks' lambda in the table is its value for the overall model if the respective variable were removed. The analysis was performed on 4 body measurements of 109 pairs of birds

\begin{tabular}{|lccc|}
\hline Predictor & Wilks' lambda & $F_{4,215}$ & $\mathrm{p}$ \\
\hline Bill length & 0.596 & 85.803 & $<0.0001$ \\
Bill depth & 0.520 & 47.894 & $<0.0001$ \\
\hline
\end{tabular}


Table 2. Spheniscus demersus. Morphometric parameters for the African penguin (females: N = 167; males: N = 166; Student's $t$-test). Sexual size dimorphism (SSD) is expressed as the sex difference in the male trait over the female trait

\begin{tabular}{|c|c|c|c|c|c|c|c|}
\hline \multirow{2}{*}{ Parameter } & \multicolumn{2}{|c|}{ Females } & \multicolumn{2}{|c|}{ Males $\longrightarrow$} & \multirow{2}{*}{$\begin{array}{c}\text { SSD } \\
(\%)\end{array}$} & \multirow{2}{*}{$t$} & \multirow{2}{*}{$\mathrm{p}$} \\
\hline & Mean $\pm \mathrm{SE}$ & Range & Mean \pm SE & Range & & & \\
\hline Bill length (mm) & $55.5 \pm 2.4$ & $49.1-66.6$ & $60.3 \pm 2.7$ & $50.6-69$ & 8.6 & -17.09 & $<0.001$ \\
\hline Bill depth (mm) & $23.3 \pm 1.4$ & $20.0-27.1$ & $25.9 \pm 1.4$ & $21.9-29.4$ & 11.2 & -16.73 & $<0.001$ \\
\hline Flipper length (mm) & $180.5 \pm 6.1$ & $165-200$ & $190.6 \pm 6.2$ & $174-215$ & 5.6 & -14.85 & $<0.001$ \\
\hline Body mass $(\mathrm{g})$ & $2996 \pm 278$ & $2275-3800$ & $3452 \pm 330$ & $2350-4625$ & 15.2 & -13.58 & $<0.001$ \\
\hline
\end{tabular}
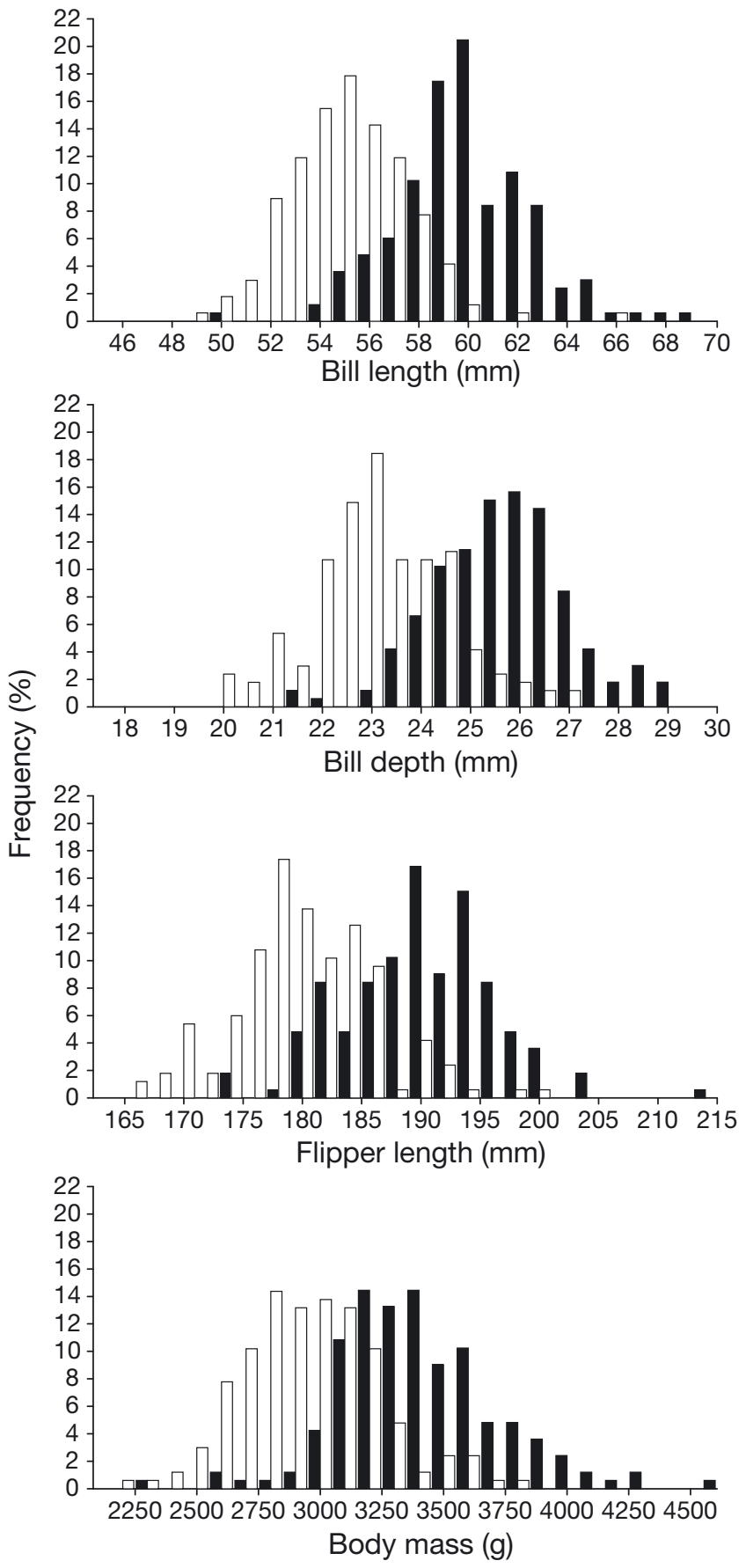

\section{Sexual differences in foraging behaviour}

Data on at-sea behaviour were collected for a total of 115 African penguins. On Bird Island, at-sea behaviour was collected for 35 birds (19 females and 16 males) in March and April 2009 and 43 birds (26 females and 17 males) in May and June 2010. On St Croix Island, at-sea behaviour was collected for 15 birds ( 7 females and 8 males) in 2009 and 22 birds (11 females and 11 males) in 2010. A total of 36250 dives was recorded over the study period (21 540 made by females and 14710 by males).

The 2 sexes did not exhibit significant differences in foraging effort, such as trip duration, path length covered and maximum distance from the colony (Table 3 and see Table S1 in the supplement at www. int-res.com/articles/suppl/n019p255_supp.pdf). Rather, foraging effort differed between colonies and years, and increased with clutch mass. Penguins from St Croix Island consistently showed a higher foraging effort than birds from Bird Island, and birds from both colonies increased their effort in 2010 compared to 2009. Sexual differences in at-sea behaviour of African penguins appeared in their diving behaviour and the size of areas exploited. Although maximum dive depth and duration were broadly similar between the sexes, males dived significantly deeper and longer on average than females (Fig. 2, Tables 3, S1 \& S2). Females, on the other hand, performed more dives per hour spent at sea than males (Fig. 2, Tables 3, S1 \& S2).

Females from both colonies and during both years consistently exploited larger areas than males (Table 4, Fig. 3), with their total foraging range being up to $50 \%$ larger than that of males (from St Croix Island in 2009, Table 4). The size of the foraging area for both sexes differed between islands and years

Fig. 1. Spheniscus demersus. Frequency distribution of bill length, bill depth, flipper length and body mass according to sex in the African penguin. Females (white bars; $N=167$ ), males (black bars; $\mathrm{N}=166$ ) 
Table 3. Spheniscus demersus. Foraging parameters (mean \pm SD and range or maximum depth/duration) for female and male African penguins rearing chicks on St Croix and Bird Islands in 2009 and 2010. Clutch mass: cumulative mass of chicks per nest. The level of significance is shown for the different fixed effects used in the models testing the effect of sex on foraging behaviour: ns: $\mathrm{p}>0.1,{ }^{*} \mathrm{p}<0.1$, ${ }^{* *} \mathrm{p}<0.05,{ }^{* * *} \mathrm{p}<0.01,{ }^{* * * *} \mathrm{p}<0.001$. nd: not determined

\begin{tabular}{|c|c|c|c|c|c|c|c|c|c|c|c|c|}
\hline \multirow[t]{2}{*}{ Parameter } & \multicolumn{4}{|c|}{$\longrightarrow$ St Croix Island $\longrightarrow$} & \multicolumn{4}{|c|}{$\longrightarrow$ Bird Island -} & \multicolumn{3}{|c|}{ _ Significance } & \multirow[b]{2}{*}{ Island } \\
\hline & $\begin{array}{c}20 \\
\text { Females } \\
(\mathrm{N}=7)\end{array}$ & $\begin{array}{c}\text { Males } \\
(\mathrm{N}=8)\end{array}$ & $\begin{array}{c}20 \\
\text { Females } \\
(\mathrm{N}=11)\end{array}$ & $\begin{array}{c}10 \text { Males } \\
(\mathrm{N}=11)\end{array}$ & $\begin{array}{c}20 \\
\text { Females } \\
(\mathrm{N}=19)\end{array}$ & $\begin{array}{c}\text { Males } \\
(\mathrm{N}=16)\end{array}$ & $\begin{array}{c}201 \\
\text { Females } \\
(\mathrm{N}=28)\end{array}$ & $10 \begin{array}{c}\text { Males } \\
\quad(\mathrm{N}=17)\end{array}$ & Sex & $\begin{array}{l}\text { Clutch } \\
\text { mass }\end{array}$ & Year & \\
\hline $\begin{array}{l}\text { Foraging trip } \\
\text { duration (h) }\end{array}$ & $\begin{array}{c}19.1 \pm 3.4 \\
(13.0-23.0)\end{array}$ & $\begin{array}{l}15.4 \pm 3.9 \\
(7.8-20.3)\end{array}$ & $\begin{array}{l}31.6 \pm 11.5 \\
(17.3-51.0)\end{array}$ & $\begin{array}{c}22.6-4.6 \\
(14.7-29.8)\end{array}$ & $\begin{array}{l}17.2 \pm 5.5 \\
(7.2-30.0)\end{array}$ & $\begin{array}{c}18.8 \pm 4.6 \\
(12.0-26.0)\end{array}$ & $\begin{array}{l}21.1 \pm 5.0 \\
(11-30.1)\end{array}$ & $\begin{array}{l}19.8 \pm 9.2 \\
(5.6-47.1)\end{array}$ & $\mathrm{ns}$ & * & $* * *$ & * \\
\hline $\begin{array}{l}\text { Trip foraging } \\
\text { path length }(\mathrm{km})\end{array}$ & $\begin{array}{l}57.1 \pm 12.9 \\
(41.3-77.5)\end{array}$ & $\begin{array}{l}44.0 \pm 18.4 \\
(11.2-68.7)\end{array}$ & $\begin{array}{c}78.4 \pm 29.9 \\
(41.3-144.1)\end{array}$ & $\begin{array}{l}60.0 \pm 18.2 \\
(31.6-91.2)\end{array}$ & $\begin{array}{l}42.9 \pm 13.8 \\
(10.9-59.8)\end{array}$ & $\begin{array}{c}40.0 \pm 9.8 \\
(25.5-54.7)\end{array}$ & $\begin{array}{c}51.7 \pm 20.0 \\
(30.2-105.1)\end{array}$ & $\begin{array}{c}54.4 . \pm 29.7 \\
(19.4-143.6)\end{array}$ & $\mathrm{ns}$ & $* * *$ & $* * *$ & $* *$ \\
\hline $\begin{array}{l}\text { Max trip distance } \\
\text { from nest }(\mathrm{km})\end{array}$ & $\begin{array}{c}22.6 \pm 5.9 \\
(15.5-30.7)\end{array}$ & $\begin{array}{l}17.1 \pm 7.6 \\
(4.7-30.6)\end{array}$ & $\begin{array}{c}26.1 \pm 7.4 \\
(14.5-39.1)\end{array}$ & $\begin{array}{l}23.7 \pm 8.3 \\
(6.7-34.5)\end{array}$ & $\begin{array}{l}14.0 \pm 5.0 \\
(4.1-24.8)\end{array}$ & $\begin{array}{l}14.1 \pm 5.1 \\
(8.6-23.2)\end{array}$ & $\begin{array}{c}16.3 \pm 8.9 \\
(7.4-43.2)\end{array}$ & $\begin{array}{l}13.5 \pm 6.0 \\
(6.0-25.1)\end{array}$ & ns & $* *$ & ns & $* * * *$ \\
\hline $\begin{array}{r}\text { Diving rate } \\
\left(\text { dives } \mathrm{h}^{-1}\right)\end{array}$ & $\begin{array}{c}16.3 \pm 2.6 \\
(13.2-20.7)\end{array}$ & $\begin{array}{l}13.2 \pm 2.6 \\
(8.9-16.3)\end{array}$ & $\begin{array}{c}15.1 \pm 4.2 \\
(11.2-24.1)\end{array}$ & $\begin{array}{l}14.0 \pm 3.7 \\
(9.4-22.9)\end{array}$ & $\begin{array}{c}21.0 \pm 5.5 \\
(13.1-32.8)\end{array}$ & $\begin{array}{l}16.8 \pm 4.1 \\
(8.1-23.6)\end{array}$ & $\begin{array}{c}17.5 \pm 5.0 \\
(11.0-28.5)\end{array}$ & $\begin{array}{c}14.6 \pm 3.7 \\
(10.2-23.7)\end{array}$ & $* * *$ & ns & $* *$ & * \\
\hline $\begin{array}{l}\text { Vertical distance } \\
\text { travelled }(\mathrm{km})\end{array}$ & $\begin{array}{c}14.3 \pm 2.5 \\
(10.7-16.5)\end{array}$ & $\begin{array}{c}9.9 \pm 2.4 \\
(6.9-13.6)\end{array}$ & $\begin{array}{c}25.9 \pm 7.6 \\
(17.1-38.0)\end{array}$ & $\begin{array}{c}19.8 \pm 2.2 \\
(13.8-21.9)\end{array}$ & $\begin{array}{l}17.5 \pm 4.9 \\
(9.3-40.2)\end{array}$ & $\begin{array}{c}18.9 \pm 7.3 \\
(11.2-40.2)\end{array}$ & $\begin{array}{c}18.4 \pm 4.6 \\
(10.4-28.7)\end{array}$ & $\begin{array}{l}17.7 \pm 5.0 \\
(7.5-27.6)\end{array}$ & ns & ns & $* *$ & ns \\
\hline Dive depth (m) & $\begin{array}{c}22.5 \pm 4.3 \\
(\max : 59.9)\end{array}$ & $\begin{array}{c}27.1 \pm 8.3 \\
(\max : 76.6)\end{array}$ & $\begin{array}{c}31.1 \pm 7.8 \\
(\max : 76.1)\end{array}$ & $\begin{array}{c}33.1 \pm 6.1 \\
(\max : 68.6)\end{array}$ & $\begin{array}{c}26.3 \pm 6.9 \\
(\max : 86.2)\end{array}$ & $\begin{array}{c}27.5 \pm 7.0 \\
(\max : 91.0)\end{array}$ & $\begin{array}{c}25.7 \pm 7.9 \\
(\max : 84.1)\end{array}$ & $\begin{array}{l}33.1 \pm 10.7 \\
(\max : 92.7)\end{array}$ & $* * *$ & nd & $* *$ & ns \\
\hline Dive duration (s) & $\begin{array}{c}68.4 \pm 7.4 \\
(\max : 134)\end{array}$ & $\begin{array}{l}80.8 \pm 13.4 \\
(\max : 153)\end{array}$ & $\begin{array}{l}84.2 \pm 15.9 \\
(\max : 173)\end{array}$ & $\begin{array}{l}89.2 \pm 13.8 \\
(\max : 167)\end{array}$ & $\begin{array}{l}76.7 \pm 11.8 \\
(\max : 275)\end{array}$ & $\begin{array}{c}80.2 \pm 9.1 \\
(\max : 266)\end{array}$ & $\begin{array}{l}74.2 \pm 12.8 \\
(\max : 227)\end{array}$ & $\begin{array}{l}87.0 \pm 13.7 \\
(\max : 175)\end{array}$ & $* * * *$ & nd & $* *$ & ns \\
\hline
\end{tabular}

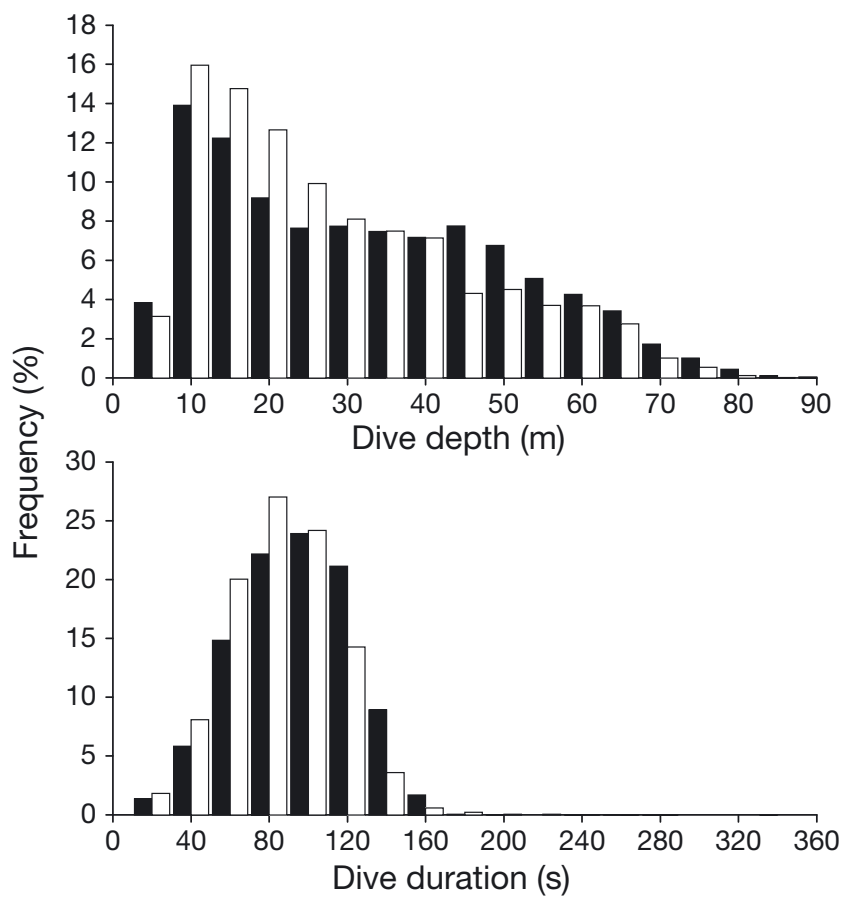

Fig. 2. Spheniscus demersus. Frequency distribution of dive depth $(\mathrm{m})$ and dive duration (s) in female (white bars, $\mathrm{N}=$ 21540 ) and male African penguins (black bars, $\mathrm{N}=14710$ )

(generally larger for penguins from St Croix than from Bird, and larger in 2010 than 2009), but the proportion of overlap between the foraging areas of males and females was independent of the actual size of the area exploited. For example, in 2010, when adults from both colonies explored larger areas, male and female penguins from Bird Island foraged in rather segregated areas ( $35 \%$ overlap), while foraging habitats of both sexes from St Croix overlapped extensively (83\%). The opposite occurred in 2009 , with foraging areas of male and female penguins from Bird Island overlapping more than the areas of birds from St Croix Island.

\section{DISCUSSION}

\section{Use of bill length and bill depth for sexing African penguins}

The accurate determination of sex from cloaca measurements even when laying dates were unknown suggests that vents from female African penguins remain distorted for a potentially long time after egg-laying (i.e. 3 to $4 \mathrm{wk}$ ). This makes sex determination using the vent reliable for African penguins, even though the method remains restricted to the incubation period. With a discriminant function analysis, we generated 2 simple classification functions using the combination of only 2 morphometric traits, bill length and bill depth, to discriminate sexes with the greatest accuracy ( $90 \%$ chance of success, Table 1), without the need to measure the body mass, which varies with body condition. These simple functions thus allow reliable sexing of any adult individual in the field, inside or outside the breeding season, with a high degree of reliability. 
Table 4. Spheniscus demersus. Total foraging areas (minimum convex polygon: $100 \%$ ) of female and male African penguins breeding on St Croix and Bird Islands in 2009 and 2010. The proportion (\%) of area used by both males and females (overlap) compared to the total area used by all birds from the colony is also shown, as well as the proportion (\%) of the total area only used by a single sex. Number of individuals as in Table 3

\begin{tabular}{|c|c|c|c|c|c|c|c|c|}
\hline \multirow[t]{3}{*}{ Parameter } & \multicolumn{4}{|c|}{$\longrightarrow$ St Croix Island } & \multicolumn{4}{|c|}{$\longrightarrow$ Bird Island } \\
\hline & \multicolumn{2}{|c|}{-2009} & \multicolumn{2}{|c|}{2010} & \multicolumn{2}{|c|}{$-2009-$} & \multicolumn{2}{|c|}{2010} \\
\hline & Females & Males & Females & Males & Females & Males & Females & Males \\
\hline Total foraging range $\left(\mathrm{km}^{2}\right)$ & 476 & 253 & 1013 & 953 & 375 & 294 & 932 & 811 \\
\hline Overlap (\%) & 50 & 83 & 69.3 & 25.6 & & & & \\
\hline Proportion used by single sex (\%) & 47.9 & 2.1 & 11.3 & 5.7 & 25.6 & 5.1 & 41.7 & 32.8 \\
\hline
\end{tabular}

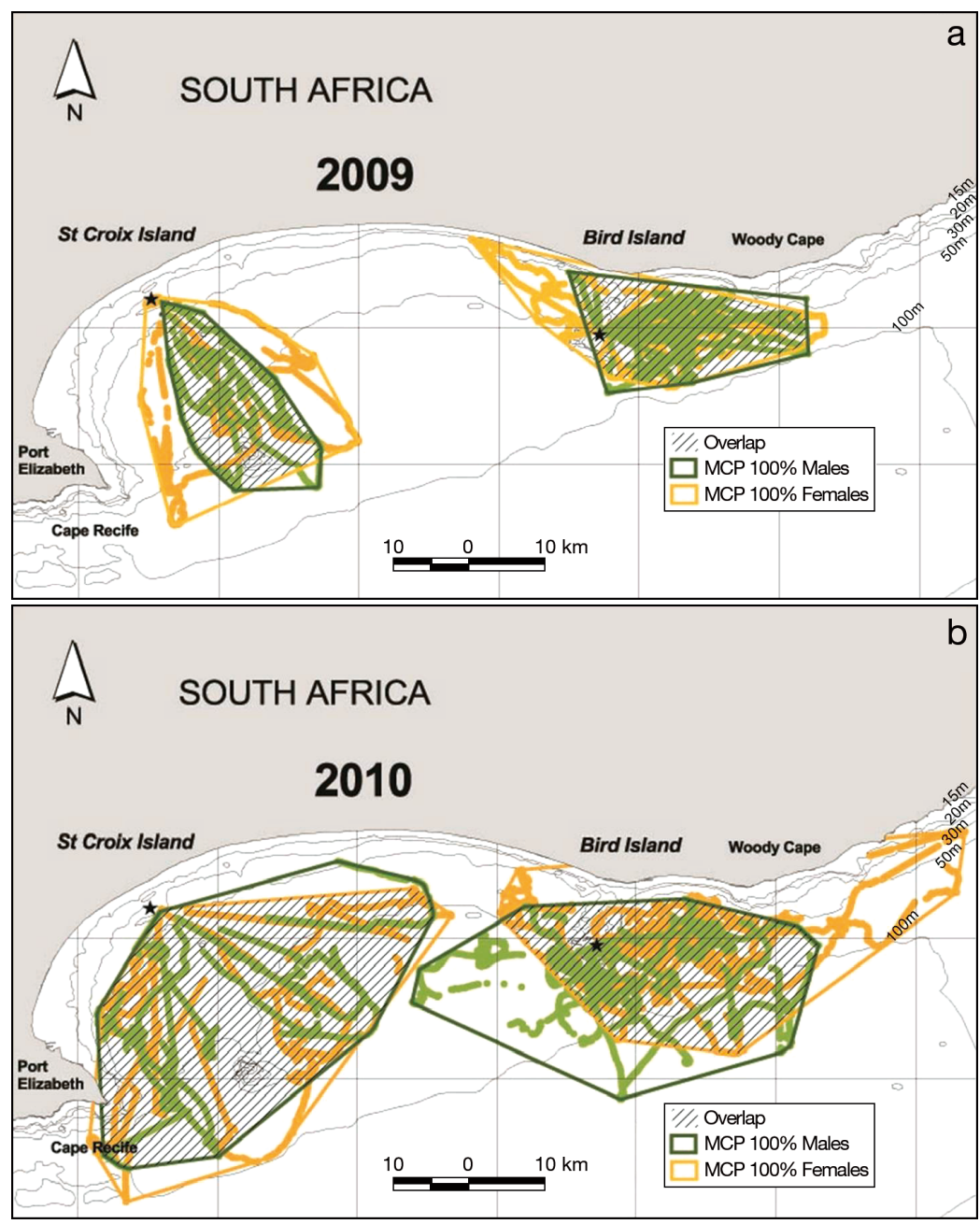

Fig. 3. Spheniscus demersus. Foraging range (minimum convex polygon. MCP: $100 \%$ ) of male and female African penguins breeding on St Croix and Bird Islands, showing the overlap (shaded areas) between sexes in (a) 2009 and (b) 2010

Most other studies using similar discriminant analyses to separate sexes of spheniscids with $>90 \%$ confidence also relied on beak measurements (e.g. bill length and depth for rockhopper penguins, Pois- bleau et al. 2010). However, the functions generated may not always be applicable to the entire range of the species, because variability in morphology can arise from geographic variation or even inter-observer bias (see Renner et al. 1998, Vanstreels et al. 2011). In our study, however, our values of bill length for each sex were identical to those previously measured by Cooper (1972) for African penguins from Dassen Island situated $850 \mathrm{~km}$ from our study sites, suggesting that body size of birds is similar despite geographical differences in body condition (L. Pichegru unpublished data) and that classification functions derived from the present study could be used on adult African penguins from other localities in South Africa.

\section{Behavioural differences at sea}

In contradiction to our hypothesis that males would travel farther because travelling costs decrease with body size, foraging effort (foraging trip duration, horizontal path length, maximum distance from the colony and vertical travel distance) was higher in females but varied more importantly between years and colonies than between sexes (Table 3), presumably in response to changes in local prey availability as well as potential intra-specific competition within colonies of different sizes (Lewis et al. 2001). African penguins feed on small pelagic fish, the abundance of which can vary markedly between years, as their recruit- 
ment is highly dependent on physical parameters of the environment (Checkley et al. 2009). Being endemic, African penguins have developed flexibility in foraging strategies to face local variability in abundant resources. Clutch mass was also an important parameter explaining variation in foraging distance and duration, with both male and female African penguins increasing their effort with chick size. This pattern is generally expected in parents adjusting the amount of food delivered to meet the needs of their offspring (Drent \& Daan 1980).

Significant differences between sexes were apparent in diving behaviour. Males dived deeper and longer on average than females (Table 3), probably because their larger body size allows larger body reserves and lower metabolic rates (Halsey et al. 2006). Similarly, larger Magellanic penguins generally dived deeper than smaller individuals, independently of sex (Walker \& Boersma 2003). However, the absence of differences in maximum diving capacities in this study suggests that diving at different depths could be related to differences in body size and be part of an active 'niche partitioning' mechanism (sensu Wearmouth \& Sims 2008) in order to reduce intra-specific competition, with the sexes feeding predominantly at different levels in the water column, particularly when resources are scarce. Raya Rey et al. (2012) found that male Magellanic penguins only dived deeper than females during the incubation period, which is associated with longer foraging trip duration, when prey availability is presumably lower. The increased diving frequency of females (Table 3 ) is presumably a compensating mechanism, which allowed them to explore similar volumes of the water column to males (similar VTD, Table 3). Such mechanisms have been noted in other species, such as brown boobies Sula leucogaster (Lewis et al. 2005) and macaroni penguins (Green et al. 2005).

Foraging effort of females was consistently higher than that of males on both islands in both years of our study, even though the differences were not significant (Table 3). They consistently foraged over wider areas than males (Fig. 3, Table 4), which may further support the hypothesis of an active strategy to reduce intra-specific competition. Overlaps between the foraging areas of males and females seemed also to depend on changes in prey availability and the physical parameters of the environment. For example, in 2009, when prey availability seemed to be higher compared to 2010 (Pichegru et al. 2012), foraging areas of males from both islands were systematically included in those of females (Fig. 3), with only 2.1 and $5.1 \%$ of the total foraging area explored exclusively by males from St Croix and Bird islands, respectively (Table 4). According to the niche partitioning hypothesis, less profitable environmental conditions in 2010 would have forced sexes to reduce intra-specific competition. Indeed, foraging areas of birds from Bird Island were largely segregated between sexes, with males foraging farther south and females farther east (Fig. 3). On the other hand, segregation was not as marked at St Croix Island, which could be due to the physical characteristics of the environment that constrained foraging flexibility: St Croix Island is much more enclosed in the bay than Bird Island, which lies at the edge of the bay, so that penguins from St Croix may have access to a more limited range of habitats.

The ability of females to explore larger areas at sea could also reflect a greater flexibility in locating resources compared to males, and/or a greater ability to adjust their behaviour with chick needs and body condition ('responsiveness to solicitation', Quillfeldt et al. 2004). Despite the relatively small sample size of equipped birds, our study females consistently explored larger areas than males, which probably exposes them to a wider variety of threats (e.g. Bugoni et al. 2010), such as by-catch, chronic oil spills or predation. Higher foraging effort while sampling a larger foraging area is certainly more energetically demanding on African penguin females. Increased foraging distance is known to decrease the chances of successful breeding in the closely related Magellanic penguins (Boersma \& Rebstock 2009). Such behaviour could imply differential parental investment between sexes, with consequences for the survival of females being apparent only after the breeding season. For example, despite similar nest attendance patterns between sexes, female gentoo penguins lose more weight at the end of the breeding season than males, probably because they give more food to the chicks (Lescroël et al. 2009). Such body depletion may induce lower inter-annual survival of females, as observed in Adélie penguins (Ainley \& de Master 1980), which results from sex-biased winter mortality. Evidence of higher female mortality in winter also exists for the congeneric Magellanic penguins (Reis et al. 2011), and may reflect lower resilience of females due to their smaller body size and larger effort during the breeding season (Raya Rey et al. 2012). Sexbiased mortality can have major consequences for population dynamics and declines in seabirds (Mills \& Ryan 2005). The conservation status of the African penguin is of such concern that the possibility of 
sex-biased winter mortality should be investigated as a matter of urgency. Studies investigating variability in adult body condition at the end of the breeding season, as well as differential oiling and survival of male and female penguins admitted to rehabilitation centres during winter, could increase our understanding of the ecology of, and potential threats to, this species.

\section{CONCLUSIONS}

Differences in at-sea behaviour between sexes are less frequently observed in the Spheniscidae than in other seabirds such as the Procellariidae or Diomedeidae (Wearmouth \& Sims 2008), possibly because their flightlessness reduces foraging flexibility. However, all penguins exhibit some degree of sexual size dimorphism, probably as a consequence of sexual selection (Serrano-Meneses \& Székely 2006). In African penguins, males arrive earlier at the colony and are more engaged in territorial activities and aggressive behaviours than females (Hockey et al. 2005), which should favour the selection of larger males. As a consequence, the discrepancy in size between sexes may favour differences in mean dive depth, which in turn would help reduce intra-sexual competition, thus indirectly reinforcing selection for greater sexual size dimorphism (Shine 1989). However, such mechanisms, if they occur, could force the smaller sex to take greater risks, such as foraging over larger areas. Our preliminary results on sexual differences in at-sea behaviour of breeding African penguins raise questions of importance for the fundamental biology and the conservation of this Endangered species, and we strongly encourage taking into account the sex of the individuals studied in any further research on this species.

Acknowledgements. This study was supported financially and logistically by the Percy FitzPatrick Institute, DST/NRF Centre of Excellence, the Department of Zoology of Rhodes University, the African Penguin Species Champion project of the Charles van der Merwe Trust, RaggyCharters, SAEON and South African National Parks. This work is based upon research supported by the South African Research Chairs Initiative of the Department of Science and Technology and the National Research Foundation. The study was conducted under permits issued by South African National Parks (PICL578), and the methods used were approved by the ethic committees of the University of Cape Town (2009/V2R/LP) and Rhodes University. We thank 4 anonymous referees for constructive comments on a previous version of the manuscript.

\section{LITERATURE CITED}

Ainley DG, DeMaster DP (1980) Survival and mortality in a population of Adélie penguins. Ecology 61:522-530

Ainley DG, Emison WB (1972) The sexual size dimorphism in Adélie penguins. Ibis 114:267-271

> Barlow K, Croxall JP (2002) Provisioning behaviour of Macaroni penguins Eudyptes chrysolophus. Ibis 144: 248-258

> Beaulieu M, Spee M, Lazin D, Ropert-Coudert Y, Le Maho Y, Ancel A, Raclot T (2010) Ecophysiological response of Adélie penguins facing an experimental increase in breeding constraints. J Exp Biol 213:33-39

> Bethge P, Nicol S, Culik BM, Wilson RP (1997) Diving behaviour and energetics in breeding little penguins (Eudyptula minor). J Zool (Lond) 242:483-502

Boersma PD, Davies EM (1987) Sexing monomorphic birds by vent measurements. Auk 104:779-783

Boersma PD, Rebstock GA (2009) Foraging distance affects reproductive success in Magellanic penguins. Mar Ecol Prog Ser 375:263-275

Bugoni L, Griffiths K, Furness RW (2010) Sex-biased incidental mortality of albatrosses and petrels in long-line fisheries: differential distributions at sea or differential access to baits mediated by sexual size dimorphism. J Ornithol 152:261-268

Checkley DM, Alheit J, Oozeki Y, Roy C (2009) Climate change and small pelagic fish. Cambridge University Press, Cambridge

Clarke J, Manly B, Kerry K, Gardner H, Franchi E, Corsolini S, Focardi S (1998) Sex differences in Adélie penguin foraging strategies. Polar Biol 20:248-258

Cooper J (1972) Sexing the jackass penguin. SAFRING News 1:23-25

> Crawford RJM, Altwegg R, Barham BJ, Barham PJ and others (2011) Collapse of South Africa's penguins in the early 21st century: a consideration of food availability. Afr J Mar Sci 33:139-156

Dale S (2001) Female-biased dispersal, low female recruitment, unpaired males, and the extinction of small and isolated bird populations. Oikos 92:344-356

$>$ Dehnhard N, Voigt CC, Poisbleau M, Demongin L, Quillfeldt P (2011) Stable isotopes in southern rockhopper penguins: foraging areas and sexual differences in the non-breeding period. Polar Biol 34:1763-1773

Drent R, Daan S (1980) The prudent parent: energetic adjustment in avian breeding. Ardea 68:225-252

> Fairbairn J, Shine R (1993) Patterns of sexual dimorphism in seabirds of the southern hemisphere. Oikos 68:139-145

> Forero MG, Hobson KA, Bortolotti GR, Donázar JA, Bertellotti M, Blanco G (2002) Food resource utilisation by the Magellanic penguin evaluated through stable-isotope analysis: segregation by sex and age and influence on offspring quality. Mar Ecol Prog Ser 234:289-299

> Fraser GS, Jones IL, Hunter FM (2002) Male-female difference in parental care in monogamous crested auklets. Condor 104:413-423

> Fridolfsson AK, Ellegren H (1999) A simple and universal method for molecular sexing of non-ratite birds. J Avian Biol 30:116-121

González-Solís J, Croxall JP (2005) Differences in foraging behaviour and feeding ecology in giant petrels. In: Ruckstuhl KE, Neuhaus P (eds) Sexual segregation in vertebrates: ecology of the two sexes. Cambridge University Press, Cambridge, p 92-111 
Green JA, Boyd IL, Woakes AJ, Warren NL, Butler PJ (2005) Behavioural flexibility during year-round foraging in macaroni penguins. Mar Ecol Prog Ser 296:183-196

Halsey LG, Butler PJ, Blackburn TM (2006) A phylogenetic analysis of the allometry of diving. Am Nat 167:276-287

Hockey PAR, Dean WRJ, Ryan PG (2005) Roberts birds of southern Africa, 7th edn. Trustees of the John Voelcker Bird Book Fund, Cape Town

> Horning M, Trillmich F (1997) Ontogeny of diving behaviour in the Galápagos fur seal. Behaviour 134:1211-1257

Jennrich RI (1977) Stepwise discriminant analysis. In: Enslein K, Ralston A, Wilf HS (eds) Statistical methods for digital computers. Wiley, New York, NY, p 76-95

Lescroël A, Bajzak C, Bost CA (2009) Breeding ecology of the gentoo penguin Pygoscelis papua at the Kerguelen Archipelago. Polar Biol 32:1495-1505

Lewis S, Sherratt TN, Hamer KC, Wanless S (2001) Evidence for intra-specific competition for food in a pelagic seabird. Nature 412:816-819

Lewis S, Schreiber EA, Daunt F, Schenk GA and others (2005) Sex-specific foraging behaviour in tropical boobies: Does size matter? Ibis 147:408-414

Lima SL, Dill LM (1990) Behavioural decisions made under the risk of predation. Can J Zool 68:619-640

Mills MSL, Ryan PG (2005) Modelling impacts of long-line fishing: What are the effects of pair-bond disruption and sex-biased mortality on albatross fecundity? Anim Conserv 8:359-367

Pichegru L, Grémillet D, Crawford RJM, Ryan PG (2010) Marine no-take zone rapidly benefits threatened penguin. Biol Lett 6:498-501

Pichegru L, Ryan PG, van Eeden R, Reid T, Grémillet D, Wanless R (2012) Industrial fishing, no-take zones and endangered penguins. Biol Conserv 156:117-125

Poisbleau M, Demongin L, van Noordwijk HJ, Strange IJ, Quillfeldt P (2010) Sexual dimorphism and use of morphological measurements to sex adults, immatures and chicks of rockhopper penguins. Ardea 98:217-224

Pütz K, Schiavini A, Raya Rey A, Lüthi BH (2007) Winter migration of Magellanic penguins (Spheniscus magellanicus) form the southernmost distributional range. Mar Biol 152:1227-1235

Quillfeldt P, Masello JF, Hamer KC (2004) Sex differences and provisioning rules and honest signalling of need in Manx shearwaters, Puffinus puffinus. Anim Behav 68: 613-620

Raya Rey A, Bost CA, Schiavini A, Pütz K (2010) Foraging movements of Magellanic penguins Spheniscus magellanicus in the Beagle Channel, Argentina, related to tide and tidal currents. J Ornithol 151:933-943

Raya Rey A, Pütz K, Scioscia G, Lüthi B, Schiavini A (2012) Sexual differences in the foraging behaviour of Magellanic penguins related to stage of breeding. Emu 112: 90-96

Reis EC, Aires RM, Moura JF, Matias CAR and others (2011)

Editorial responsibility: Rory Wilson,

Swansea, UK
Molecular sexing of unusually large numbers of Spheniscus magellanicus (Spheniscidae) washed ashore along the Brazilian coast in 2008. Genet Mol Resour 10: 3731-3737

Renner M, Valencia J, Davis LS, Saez D, Cifuentes O (1998) Sexing of adult gentoo penguins in Antarctica using morphometrics. Colon Waterbirds 21:444-449

Ryan PG, Boix-Hinzen C (1999) Consistent male-biased seabird mortality in the Patagonian toothfish fishery. Auk 116:851-854

Samour HJ, Stevenson M, Knight JA, Lawrie AJ (1983) Sexing penguins by cloacal examination. Vet Rec 113: 84-85

Schmidt-Nielsen K (1972) Locomotion: energy cost of swimming, flying, and running. Science 177:222-228

Selander RK (1966) Sexual dimorphism and differential niche utilization in birds. Condor 68:113-151

Serrano-Meneses MA, Székely T (2006) Sexual size dimorphism in seabirds: sexual selection, fecundity selection and differential niche-utilisation. Oikos 113:385-394

Shine R (1989) Ecological causes for the evolution of sexual dimorphism: a review of the evidence. Q Rev Biol 64: 419-461

Taylor SS, Leonard ML, Boness DJ, Majluf P (2002) Foraging by Humboldt penguins (Spheniscus humboldti) during the chick-rearing period: general patterns, sex differences, and recommendations to reduce incidental catches in fishing nets. Can J Zool 80:700-707

Vanstreels RET, Adornes AC, Ruoppolo V, Canabarro PL, Silva-Filho RP, Catao-Dias JL (2011) Gender determination from morphometrics in migrating Magellanic penguins (Spheniscus magellanicus). Mar Ornithol 39: 215-220

Volkman NJ, Presler P, Trivelpiece W (1980) Diets of pygoscelid penguins at King George Island, Antarctica. Condor 82:373-378

Walker BG, Boersma PD (2003) Diving behaviour of Magellanic penguins (Spheniscus magellanicus) at Punta Tombo, Argentina. Can J Zool 81:1471-1483

Welcker J, Steen H, Harding AMA, Gabrielsen GW (2009) Sex-specific provisioning behaviour in a monomorphic seabird with a bimodal foraging strategy. Ibis 151: 502-513

Wearmouth VJ, Sims DW (2008) Sexual segregation in marine fish, reptiles, birds and mammals: behaviour patterns, mechanisms and conservation implications. Adv Mar Biol 54:107-170

- Wienecke BC, Robertson G (1997) Foraging space of emperor penguins Aptenodytes forsteri in Antarctic shelf waters in winter. Mar Ecol Prog Ser 159:249-263

Williams TD (1995) The penguins: Spheniscidae. Oxford University Press, New York, NY

Wilson RP, Wilson MP (1990) Foraging ecology of breeding Spheniscus penguins. In: Davis LS, Darby JT (eds) Penguin biology. Academic Press, San Diego, CA, p 245-264

Submitted: July 17, 2012; Accepted: November 13, 2012 Proofs received from author(s): January 16, 2013 